\title{
Elevational Gradients in Species Richness
}

Christy M McCain, University of Colorado, Boulder, Colorado, USA

John-Arvid Grytnes, University of Bergen, Bergen, Norway

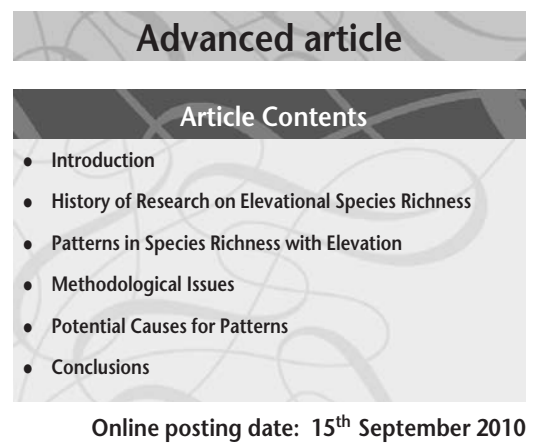

\begin{abstract}
The abiotic and biotic gradients on mountains have enormous potential to improve our understanding of species distributions, species richness patterns and conservation. Here we describe how abiotic factors change with elevation, how flora and fauna respond to these changes and how elevational species richness patterns have been studied to uncover drivers of biodiversity. There are four main trends in elevational species richness: decreasing richness with increasing elevation, plateaus in richness across low elevations then decreasing with or without a mid-elevation peak and a unimodal pattern with a mid-elevational peak. We discuss the history of elevational richness studies and overview the various hypotheses thought to be important in richness trends, including climatic, spatial, biotic and evolutionary factors.
\end{abstract}

\section{Introduction}

Mountains have long captivated mankind and have been considered sacred places in many societies, as well as popular destinations for hiking, skiing and solace. Darwin, Wallace and von Humboldt provided the first detailed observations of how the natural world changes with elevation (Lomolino, 2001). In their voyages around the world, early naturalists noted that the types of habitats and the number of species changed predictably with increases in latitude and elevation. These predictable changes in composition and diversity of the flora and fauna along latitudinal and elevational gradients have become bastions in studies of ecology and evolution.

Several factors change predictably with increasing elevation; the most obvious of which is the generally linear

ELS subject area: Ecology

How to cite:

McCain, Christy M; and Grytnes, John-Arvid (September 2010)

Elevational Gradients in Species Richness. In: Encyclopedia of Life

Sciences (ELS). John Wiley \& Sons, Ltd: Chichester.

DOI: 10.1002/9780470015902.a0022548 decrease in temperature (Figure 1a). Temperature decreases by an average of approximately $0.6^{\circ} \mathrm{C}$ for each $100 \mathrm{~m}$ increase in elevation (Barry, 2008). This is termed the moist adiabatic lapse rate and varies depending on the latitude, size, shape and prevailing weather patterns on the mountain from $0.4^{\circ} \mathrm{C}$ to $0.7^{\circ} \mathrm{C}$ for each $100 \mathrm{~m}$ increase in elevation (Barry, 2008). Tropical mountains, due to higher temperatures at low latitudes, have warmer temperatures at the base and therefore need to be much taller to reach the extreme cold temperatures seen on temperate mountains (Figure 1a). Other abiotic factors that vary predictably with elevation are air pressure, which decreases with increasing elevation, and solar radiation, which increases with increasing elevation (Barry, 2008).

Other climatic and abiotic factors vary along montane gradients but have a more complex relationship to elevation. The best example, and probably most important, of such a factor is precipitation (Figure 1b; Barry, 2008). Precipitation can be in the form of rain, snow and condensation from clouds (e.g., horizontal precipitation in cloud forests). The elevational precipitation trends tend to correspond to the prevailing weather patterns, the slope and the proximity to the ocean or a large water body (Barry, 2008). The most common elevational pattern is increasing precipitation with increasing elevation. This pattern predominates on mountains at temperate latitudes and in arid regions regardless of latitude (Figure 1b; Barry, 2008). Tropical mountains show a more variable pattern and display decreasing trends, unimodal or bimodal trends with highest precipitation at middle elevations and increasing trends. Some mountains (e.g., in Vietnam or French Guiana) show little variation in precipitation across the elevational gradient. The interaction among temperature, precipitation, cloud cover and solar radiation determine the overall productivity of an elevation and this, like precipitation alone, displays elevational trends that vary considerably among mountains. Other abiotic factors that vary with elevation and can be important determinants of species richness include area, cloud cover and soil quality, among others. For example, montane cloud forest is linked to small mammal diversity patterns and is a habitat predominantly created through the tendency of cloud cover to persist at mid- to high-elevations. Montane cloud forests vary in elevation among mountains depending on the distance to the ocean, mountain height 


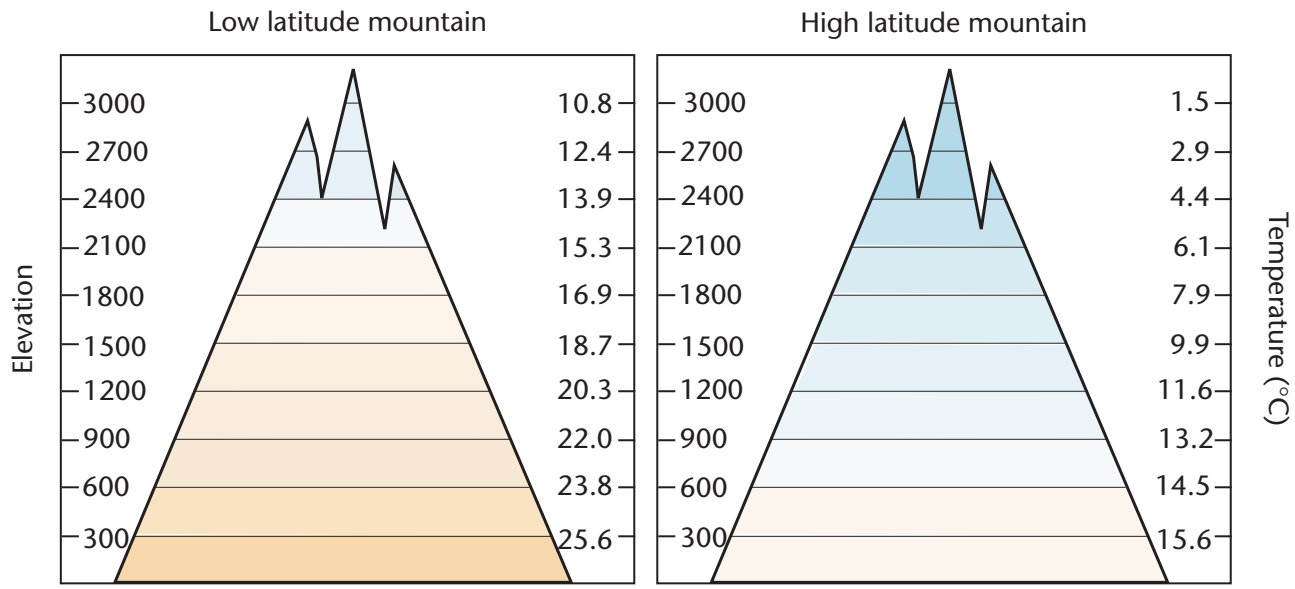

Temperature variation

(a)

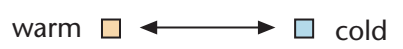

Low latitude mountain

High latitude mountain

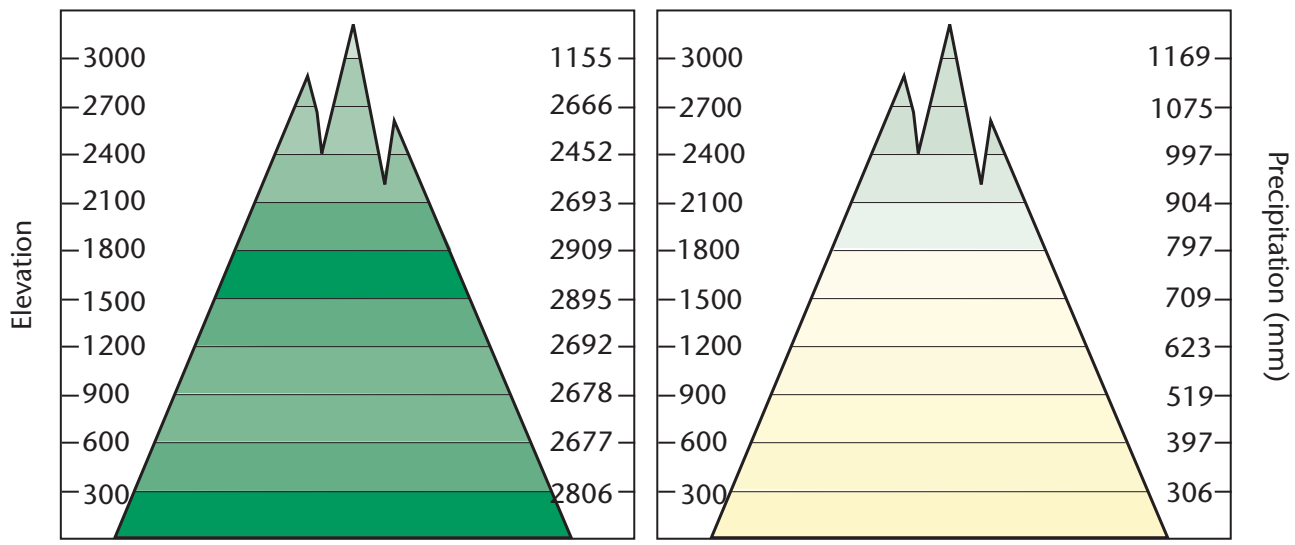

Precipitation variation

(b)

wet $\square \longleftrightarrow$ dry

Figure 1 Two examples of elevational gradients: a tropical mountain (left column; e.g., Venezuela) and a temperate mountain (right column; e.g., SW USA). (a) Temperature generally decreases linearly with elevation. Both mountains have similar wet adiabatic lapse rates of 5.68 and $5.24{ }^{\circ} \mathrm{Celsius}$ per $100 \mathrm{~m}$, respectively, but with much cooler average annual temperatures at the higher latitudes. (b) Precipitation varies greatly along elevational gradients. The tropical mountain has overall wetter conditions with peaks in precipitation at the lowest and mid-elevations, whereas the arid-based, temperate mountain shows the typical pattern of increasing precipitation with elevation. The combination of temperature and precipitation values result in habitat zonation with elevation. The tropical gradient changes from lowland tropical rainforest to premontane rainforest to montane rainforest to cloud forest, and finally elfin forest and alpine grasslands. The arid, high latitude gradient changes from desert scrub or grassland to chaparral to pinyon-pine forests to mixed hardwood-pine forests to ponderosa pine forests, and finally fir forests and alpine grasslands.

and local climatic conditions such as prevailing winds and local temperature or precipitation regimes.

The gradients in these abiotic factors strongly influence the distribution of floral and faunal species, and therefore the changes in dominant communities and habitat that we notice as we climb in elevation. It is not surprising that these dramatic changes over short distances have led ecologists to formulate many of the key ecological concepts from montane gradients, including niche theory (Grinnell, 1917), life zones (Merriam and Stejneger, 1890), community assembly (Whittaker, 1960) and insular biogeography (Brown, 1971). Elevational gradients remain mainstays for contemporary research on many topics in ecology and evolution, and are critical for our current understanding of large-scale trends in biodiversity, global change and conservation. See also: Environmental Heterogeneity: Temporal and Spatial

\section{History of Research on Elevational Species Richness}

The reduced number of species of plants and animals on mountaintops in comparison with the plethora of species in 
the lowlands was no doubt known to the earliest human societies (Lomolino, 2001). By the nineteenth century, the early naturalists including Linnaeus, Willdenow, von Humboldt, Darwin and Wallace noted that species richness decreased from low to high latitudes. And on their explorations of tropical mountains - von Humboldt and Darwin predominately in the South American Andes, and Wallace in Southeast Asian islands - noted the same trend for elevation; the number of species appeared to decrease from low to high elevations (Lomolino, 2001). It was not until the twentieth century that quantitative assessments were compiled to evaluate elevational trends in species richness. Joseph Grinnell, a vertebrate biologist at the newly founded Museum of Vertebrate Zoology at the University of California Berkeley, set out to detail the elevational distributions of terrestrial vertebrates on various mountains in California. This work is best known for his conceptual delineation of the niche (Grinnell, 1917), but in his studies the earliest recorded elevational richness patterns can also be found for the Yosemite and Lassen elevational gradients among others (Grinnell and Storer, 1924; Grinnell et al., 1930). See also: Latitudinal Diversity Gradients

Grinnell and Storer (1924) determined that each group of vertebrates on the Yosemite transect (bats, nonflying small mammals, breeding birds, amphibians and reptiles) exhibited a unimodal richness pattern with the highest species richness about a third of the way up the mountain. In contrast on Lassen, Grinnell and colleagues found that nonflying small mammals and birds had the highest number of species at mid-elevations, whereas reptiles and bats had the highest richness at the lowest elevations (Grinnell et al., 1930). Later in the century, Robert Whittaker and colleagues set about describing how insect and plant diversity changed along elevational gradients on various mountains in the United States (Whittaker, 1952, 1960). Whittaker, like Grinnell, described two elevational pattern of species richness - decreasing with elevation and midelevational richness peaks that varied among mountains and organism of study (e.g., trees, bushes and herbs; flies, beetles and grasshoppers).

In the 1970s and 1980s, ecologists became enamoured by the extraordinarily diverse tropics and attention shifted away from temperate elevational studies. The first tropical elevational gradient study to make a decisive mark on the research community was John Terborgh and colleagues' examination of bird communities in the Peruvian Andes (Terborgh and Weske, 1975; Terborgh, 1977, 1985). Like Darwin and Wallace, Terborgh detailed decreasing richness with increasing elevation in Peruvian birds and he noted the strong parallel between the latitudinal and elevational gradients in diversity. Based on these results, decreasing elevational diversity became the accepted and assumed pattern for all taxonomic groups for more than two decades (e.g., Brown and Lomolino, 1998), and the unimodal elevational patterns of Grinnell and Whittaker were largely forgotten. The uniformity of decreasing richness on elevational gradients was challenged by Rahbek
(1995). He showed that the decreasing trend in richness found by Terborgh was only from nonstandardised samples, and when samples were standardised (Figure 7 in Terborgh, 1977) a mid-elevational peak occurred. Rahbek (1995) also presented a series of case studies emphasising that unimodal trends were more common than decreasing patterns. Recently, there has been a concerted effort to systematically document species richness along elevational gradients around the world for many groups of plants and animals (Heaney, 2001; Kessler et al., 2001; Sanders, 2002; Brehm et al., 2003; Grytnes, 2003; Herzog et al., 2005). Additionally, a series of systematically compiled metaanalyses were conducted for various taxonomic groups (McCain, 2005, 2007b, 2009, 2010).

\section{Patterns in Species Richness with Elevation}

Elevational patterns in species richness fall into four common patterns: decreasing, low plateau, low plateau with a mid-elevational peak and mid-elevation peak (Figure 2; McCain, 2009). These have been variously defined and named, but here we follow the quantifiable definitions of McCain (2009). Decreasing richness patterns are those in which species numbers decline generally monotonically with increasing elevation. Low plateau patterns have consecutively high richness across the lower portion of the gradient $(>300 \mathrm{~m})$ and thereafter decreasing species richness. Low plateau patterns with a mid-elevational peak have high richness across low elevations $(>300 \mathrm{~m})$ with a diversity maximum found more than $300 \mathrm{~m}$ from the base. Mid-elevation peaks have a unimodal peak in diversity at intermediate elevations $(>300 \mathrm{~m})$ with $25 \%$ or more species than at the base and top of the mountain. Rarely, species richness increases with elevation (e.g., for salamanders and lichens in Martin, 1958; Wake et al., 1992; Grytnes et al., 2006).

As displayed in the early studies of Grinnell and Whittaker, the patterns of elevational species richness reflect the ecology of the taxonomic group (McCain, 2009, 2010). Meta-analyses of terrestrial vertebrate groups found that the predominance of a particular elevational pattern of species richness was clearly linked to taxon (Figure 2). Nonflying small mammals (e.g., rodents, shrews and tenrecs) almost ubiquitously display mid-elevational peaks in diversity (McCain, 2005), whereas bat elevational patterns were evenly split between decreasing and mid-elevational peaks (McCain, 2007b). Birds and reptiles displayed all four common patterns of elevational species richness evenly for birds (McCain, 2009), and with a predominance of decreasing patterns for reptiles (McCain, 2010). Preliminary analyses for amphibians show that salamanders displayed mostly mid-elevational peaks in species richness, whereas frogs showed all four common patterns in similar frequency. Although no meta-analyses have been completed for plants and insects, the literature shows examples 


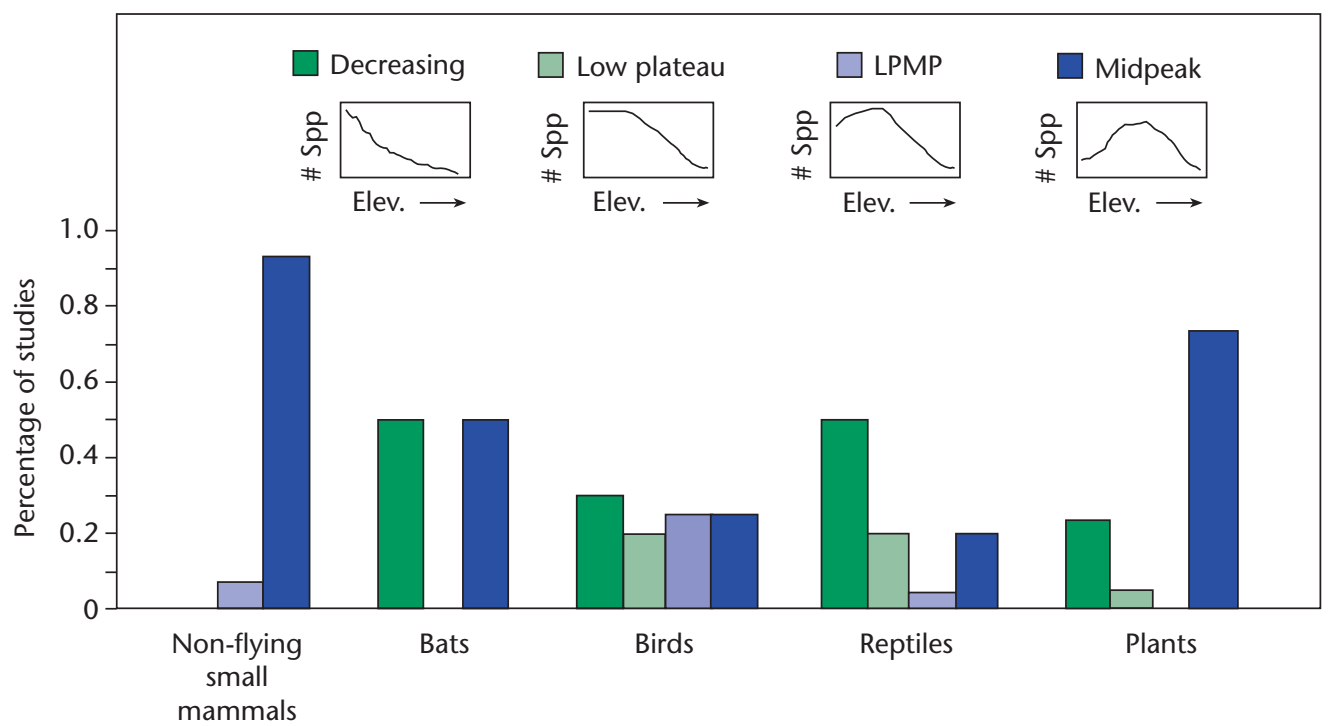

Figure 2 The percentage of the four main elevational richness patterns demonstrated on mountain gradients across the globe, including decreasing, low-elevation plateau, low-elevation plateau with a mid-peak (LPMP) and midpeak for nonflying small mammals (McCain, 2005), bats (McCain, 2007a), birds (McCain, 2009), reptiles (McCain, 2010) and plants (Rahbek, 2005 Figure 3f3). Preliminary results for salamanders and frogs are very similar to small mammals and birds respectively. A few studies of plants and frogs have found increasing richness with increasing elevation, but these appear to be quite rare.

of all four patterns among various groups. Rahbek (2005) included many plant studies in his overview of scale and species richness, and found most displayed mid-elevational peaks along elevational gradients (Figure 2). There is almost no documentation of elevational patterns of microbe diversity, although one study found a decreasing taxon diversity pattern for bacteria in the Rocky Mountains of Colorado between 2460 and $3380 \mathrm{~m}$ (Bryant et al., 2008).

Can we state decisively if one elevational diversity pattern is more common than others from the meta-analyses aforementioned? Among vertebrates, all four patterns are common: mid-elevational peaks represent $45 \%$, decreasing $26 \%$, low plateaus $15 \%$ and lastly low plateaus with midpeaks at $14 \%$. The variation in elevational patterns makes studying elevational gradients advantageous over the almost completely uniform species richness patterns along latitudinal gradients by providing multiple, independent natural experiments on the world's mountains. Based on the variation in patterns between taxonomical or functional groups, and between different mountains, we have a great tool for improving our understanding of large-scale variation in species richness.

\section{Methodological Issues}

Some of the variation in elevational diversity patterns may be due to differences in sampling, scale of study, or postsampling treatment of data. Elevational species richness is studied at two general scales - local or alpha diversity and regional or gamma diversity (Figure 3a). The local scale is typically field transects of standardised samples along single elevational gradients. The regional scale includes data compiled from sight and capture records, specimen records and field notes for an entire mountain or mountainous region. Each scale has its benefits and drawbacks. For instance, regional richness may be highly influenced by area and sampling (Rahbek, 2005; McCain, 2007a), whereas short-term transects may miss rare species or under-sample elevational ranges. Therefore, the trends at the two scales can differ quantitatively and qualitatively. Regional data often need standardisations or sampling evaluations, as they are usually not specifically designed to study elevational richness patterns. The most common standardisation is interpolation of species ranges between its highest and lowest reported elevations, but rarefaction is also an option if more detailed information about distributions of specimens is known (Grytnes and Romdal, 2008).

Sampling robustness, like all ecological field studies, is of utmost importance in accurately estimating patterns of elevational species richness. Clearly, the more sampling effort, the more confidence there will be in the species richness estimates (Gotelli and Colwell, 2001). A common sampling problem occurs when sampling effort is not spread evenly over the entire elevational gradient (Figure 3b1). If sampling is strongly biased towards one area of the mountain, then the species richness pattern can reflect this sampling bias. For example, evenly spaced sampling will show a mid-elevational peak in richness, whereas if sampling is concentrated at the lowest elevations then the estimated pattern may change to a low plateau (Figure $3 \mathbf{a} \mathbf{1}$ and $\mathbf{b} \mathbf{1}$ ). Such sampling biases might be resolved by using rarefaction (Gotelli and Colwell, 2001; Grytnes and Romdal, 2008). A second common sampling problem is gradient truncation where only a portion of the mountain 


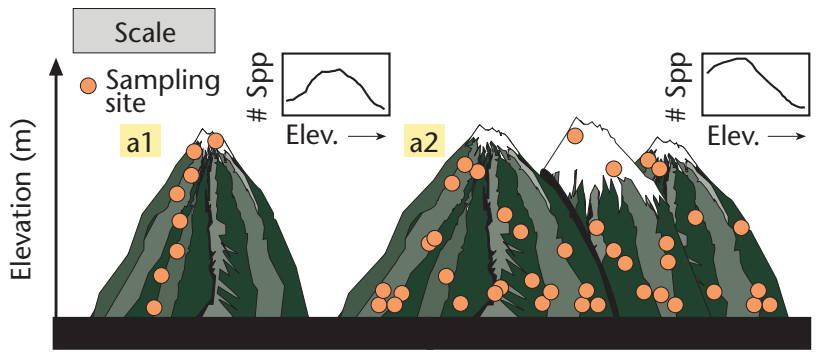

Local transect

Regional compilation
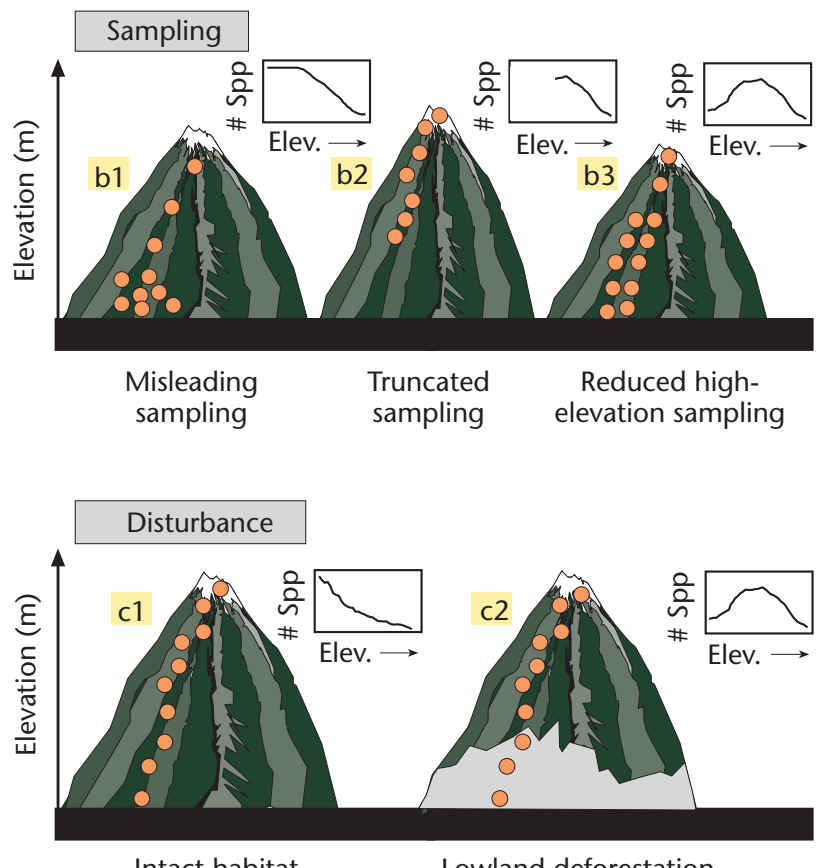

Intact habitat

Lowland deforestation

Figure 3 Studies of elevational species richness can be strongly influenced by methodological issues of scale, sampling and disturbance; here we show several examples. The scale of sampling falls into two broad categories: local transect studies which are sampled ideally at equal intervals from the base to the peak of the mountain usually within a 1-2 years (a1); and regional compilations of sampling from many researchers, slopes and years (a2). The regional compilations can be heavily influenced by the greater area at the base of mountains, thus potentially leading to more greater estimated richness at lower elevations. The distribution of sampling effort can influence the estimates of species richness by not spreading the effort evenly over the gradient (b1), which can lead to higher richness in areas of high sampling and low richness in areas of low sampling (e.g., compare a1 and b1). If sampling is only distributed over a portion of the gradient (b2), this truncation can lead to the identification of a very different pattern of species richness (e.g., compare a1 and b2). Reduced sampling at the highest elevations tends to have less influence on species richness estimates, since diversity is generally reduced at these elevations (b3). Habitat disturbance, particularly widespread and concentrated within a zone of elevation (e.g., lowlands, c2) can lead to reduced estimates of species richness in disturbed areas (e.g., compare $\mathrm{c} 1$ and c2).

was sampled (Figure 3b2; McCain, 2005; Nogués-Bravo et al., 2008). In such cases, the documented pattern can be misleading because the lower portion of the gradient is critical for pattern documentation. For example, a mid-elevational peak trend for the whole mountain will appear to be a decreasing or low plateau if only the upper half of the gradient is sampled (Figure $3 a 1$ and b2). In contrast, limited sampling at the highest elevations is less critical since diversity almost always decreases monotonically above some threshold intermediate elevation (Figure 3b3).

Sampling within large regions of habitat disturbance or fragmentation can also negatively influence the robustness of an elevational species richness pattern (Figure 3c; McCain, 2005; Nogués-Bravo et al., 2008). The most problematic instances of disturbance are when the disturbed area is elevationally concentrated (e.g., at the base or mid-elevations only). In such cases, the documented species richness at those elevations could be much lower than within intact habitat, therefore resulting in the erroneous species richness pattern (Figure 3c1 and c2).

\section{Potential Causes for Patterns}

Proposed drivers of biodiversity can be grouped into four main categories: climate, space, evolutionary history and biotic processes (Pianka, 1966; Gaston, 2000; McCain, 2007b). Many hypotheses proposed to explain global-scale patterns in species richness apply to elevational richness patterns (Table 1; McCain, 2007b, 2009). Climatic hypotheses are based on variation in abiotic variables such as temperature, rainfall, productivity, humidity and cloud cover. Spatial hypotheses include the classic species-area relationship (SAR) and spatial constraint hypothesis (middomain effect: MDE). Speciation rates, extinction rates, clade age and phylogenetic niche conservatism are theoretically linked, and in some cases, empirically linked to diversity. Lastly, various biological processes have been proposed to explain patterns in species richness, including ecotone effects, competition, mutualisms, habitat heterogeneity and habitat complexity. See also: Conservation Biology and Biodiversity; Latitudinal Diversity Gradients; Tropical Forests

\section{Space}

The SAR asserts that as survey area increases, number of species encountered increases (Rosenzweig, 1995). On mountains, SAR predicts that regions on the montane gradient covering more area, for example the mountain base, should harbour more species than regions covering smaller areas like mountain tops (Rahbek, 1997; McCain, 2007a). SAR is based on the assumption that at regional and global scales, extinction rates should decrease and speciation rates should increase with area due to the increased likelihood of barrier formation and increased population densities (Rosenzweig, 1995 and references therein). At small spatial scales, Rosenzweig (1995) argued that habitat diversity and the strong ties of particular species to habitat drive the local SAR. The elevational diversity patterns on mountains may fall somewhere on the 
Table 1 Predictions of hypotheses underlying gradients in elevational species richness

\section{Temperature}

Diversity positively related to temperature
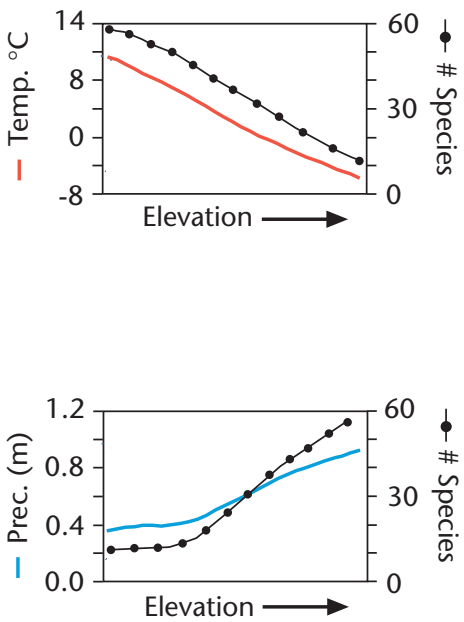

\section{Productivity}

Diversity positively related productivity
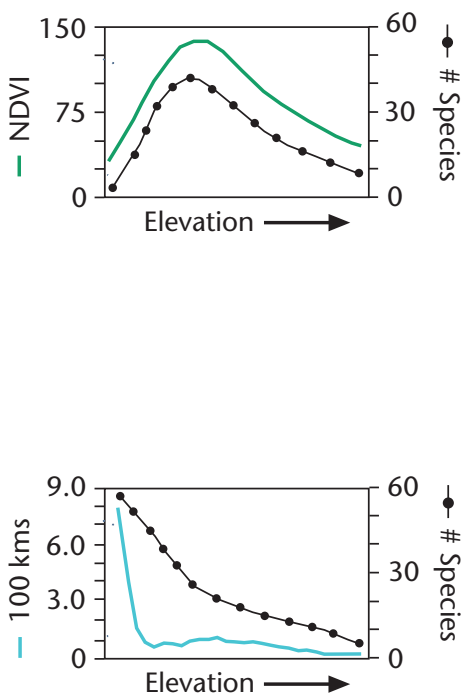

\section{Mid-domain effect}

Bounded domain creates more overlap of ranges mid-gradient

\section{Ecotone effect}

Peaks in diversity at ecotones, maximum at major ecotone
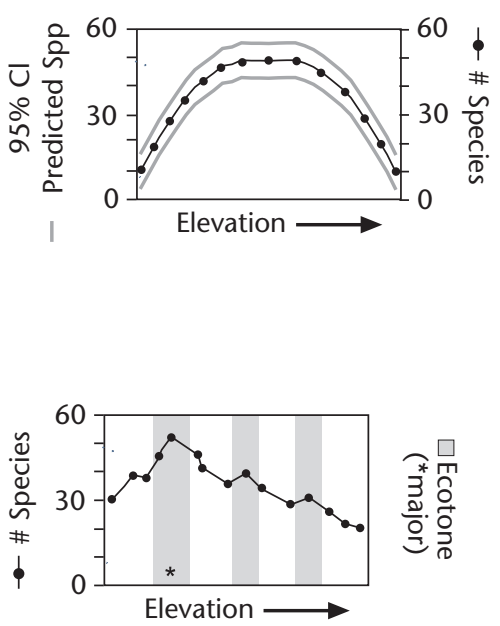

Predicted pattern: decreasing diversity

1. Metabolic theory: linear relationship with slope of -0.65

2. More-individuals: also positive relationship with populations

3. More-resources: also positive relationship with food/nutrients

Predicted pattern: variation among gradients

1. More-individuals: also positive relationship with populations

2. More-resources: also positive relationship with food/nutrients

Predicted pattern: variation among gradients

1. More-individuals: also positive relationship with populations

2. More-resources: also positive relationship with food/nutrients

3. Niche conservatism: warm-wet niches older and more widespread in the past (time-for-speciation effect)

Predicted pattern: predominantly decreasing diversity but some mid-peaks

1. Habitat heterogeniety: also positively related to area

Predicted pattern: symmetrical mid-elevation peak

1. Positive, significant relationship between MDE predictions and species richness

2. Better fits for groups of species with large range sizes relative to gradient length

Predicted pattern: variation among gradients

1. Positive, significant relationship with major and minor ecotones and species richness

2. Populations within ecotones dominated by juveniles (sink populations) 
Table 1 Continued

Biotic interactions

Species distributional

interactions
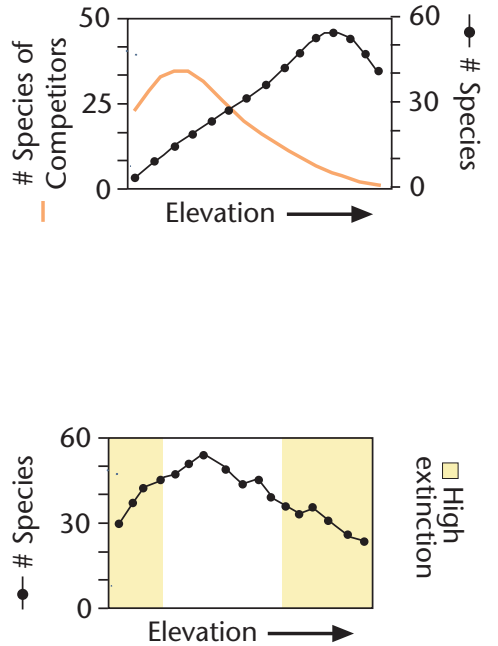

Predicted pattern: variation among gradients

1. Negative, significant relationships between inhibiting biotic factors and species richness (e.g., competitor distributions)

2. Positive, significant relationships between facilitating biotic factors and species richness (e.g., habitat heterogeneity)

Predicted pattern: depends on hypothesis

1. Low species richness in areas of high extinction pressure

2. High species richness in areas of high speciation

3. Mid-elevation refuge from fluctuating climate over evolutionary time continuum between these two scales and processes. Land area decreases with elevation on most mountains, although a minority (approximately $25 \%$ in a recent comparison) has their greatest area at mid-elevation (McCain, 2007a). These are elevational gradients in regions with highly dissected topography where the lowest elevations are within deep ravines and thus cover less area. The SAR predicts a positive relationship between area and species richness and on most gradients would be a decreasing pattern with elevation (Table 1), although in some cases may be a low plateau or mid-peak. Currently, there is mixed support for SAR along elevational gradients - some studies showing strong effects and other showing no effect or a negative trend (Sanders, 2002; McCain, 2007a, 2009, 2010). The effect of elevational area may also be visible on local scale diversity pattern (Romdal and Grytnes, 2007).

The MDE assumes that spatial boundaries (e.g., base and top of mountain) cause more overlap of species' ranges towards the centre of an area where many large- to medium-sized ranges must overlap but such overlaps are less likely towards an edge of the area (Colwell et al., 2004). MDE predicts a unimodal diversity curve with maximum diversity at the midpoint of the mountain (Grytnes and Vetaas, 2002; McCain, 2004), and a strong concordance between MDE Monte Carlo simulations and empirical diversity (e.g., mid-domain null; McCain, 2004). Lastly, MDE predicts that groups that have large range sizes relative to the length of the elevational gradient should have a stronger effect of spatial constraint (Colwell et al., 2004; McCain, 2009). This is based on the premise that MDE predictions are based mainly on the overlap of medium and large range species, and do not apply necessarily to small-ranged species (Colwell et al., 2004). So far there is little support for the predictions of MDE as sole predictor along elevational gradients, particularly among terrestrial vertebrates (McCain, 2005, 2007b, 2009, 2010).

\section{Climate}

Climate puts restrictions on how many species can survive at different locations and elevations. This restriction may be a result of physiological limits of the species - the minimum and maximum niche values within which a species can survive (e.g., temperatures or precipitation levels) - or it may limit the number of individuals - the climatic conditions restrict the productivity which in turn limits the population sizes and total number of individuals (Brown, 2001; Hawkins et al., 2003). Many aspects of climate could be important for species richness (e.g., humidity and cloud cover), but the three most commonly studied climate axes are temperature, precipitation and productivity (Table 1).

A positive relationship between temperature and species richness has been shown for many large-scale diversity patterns with several mechanisms invoked (Hawkins et al., 2003; Evans et al., 2005). As stated in the preceding text, temperature decreases with increasing elevation (Barry, 2008). If temperature is a main determinant of elevational species richness, the pattern predicted is decreasing diversity with increasing elevation (Heaney, 2001; McCain, 2007b). Several hypotheses have been proposed to explain the temperature-diversity relationship. The metabolic theory of ecology (MTE) is the theory that most directly connects diversity and temperature, and uses the biochemical kinetics of metabolism to predict changes in diversity of ectotherms along temperature gradients by linking ecological and evolutionary processes to an organism's metabolic rate (Brown et al., 2004). MTE predicts a very specific relationship between temperature and 
species richness: a negative linear relationship and the slope of the relationship is -0.65 . Solely based on Figure 2 , it is evident that a positive temperature-diversity relationship is not the most common pattern along elevational diversity gradients. Only reptiles showed a predominate temperature effect along elevational gradients worldwide (McCain, 2010). In a test of the predictions of the MTE for vertebrate ectotherms along 102 elevational gradients, there was almost no support for the metabolic temperature predictions (McCain and Sanders, 2010). Temperature is also a major determinant of productivity and may govern diversity through its effect on productivity (described in the following text).

A positive relationship between precipitation and species richness has been discussed for local and regional diversity patterns (Hawkins et al., 2003; Evans et al., 2005), although most often in conjunction with temperature (discussed in the following text for productivity). As stated in the preceding text, precipitation does not change consistently with elevation on all mountains, but varies greatly due to regional mountain and weather conditions (Barry, 2008). Therefore, along elevational gradients no single elevational diversity pattern would be predicted, but instead individualistic patterns on each mountain showing a positive relationship between precipitation and species richness (Table 1; McCain, 2007b). In the example in Table 1, a positive relationship is shown for a mountain where precipitation and species richness increase with elevation. The precipitation effect would clearly be a major determinant for plant distributions and hence for plant diversity, but for most terrestrial animal species a precipitation effect may be indirect by influencing resource availability. Owing to the difficulty in obtaining robust precipitation data along elevational gradients, it is largely unknown how well precipitation trends correspond to species richness (McCain, 2009).

Climatic productivity has also been strongly and positively linked to diversity (O'Brien, 1993; Mittelbach et al., 2001; Hawkins et al., 2003; Evans et al., 2005). Several mechanisms attempt to explain this relationship (Evans et al., 2005). Climatic productivity depends primarily on regional temperature and precipitation. Hence, elevational productivity patterns will vary among mountains and no single elevational diversity pattern is predicted. The hypothesis usually connected to productivity is the moreindividuals hypothesis, which predicts that the positive relationship between diversity and productivity is due to the ability of high productive areas to support more individuals within a community and thus, more species (Srivastava and Lawton, 1998). Alternatively, high productivity may result in increased availability of critical resources and therefore support more species. Thus, the latter two hypotheses predict a positive productivity-species richness relationship, but also a positive relationship with either the number of individuals in the local communities and/or the quantity of critical resources. Also like precipitation, there is a lack of robust productivity data along elevational gradients, and therefore little direct testing of its elevational importance (McCain, 2007b, 2009). Little research has shed light on the underlying population and resource relationships with species richness and productivity along elevational gradients, and these remain open questions.

An elevational climate model (ECM) was proposed where separate gradients in temperature and water availability on mountains in different climatic regimes predict divergent elevational diversity patterns (McCain, 2007b, 2009). The elevations with the warmest-wettest conditions should harbour the highest species richness; thus on arid mountains (e.g., southwestern US mountains), water availability follows a unimodal relationship with elevation and thus the warmest-wettest conditions are at intermediate elevations. On humid mountains (e.g., Eastern Andes), the warmest-wettest conditions are towards the base of the mountain as both water availability and temperature decrease with elevation. Therefore, this climate model predicts decreasing diversity on humid mountains and unimodal diversity on arid-based mountains. Both meta-analyses of bats and birds along elevational gradients found strong support for this hypothesis (McCain, 2007b, 2009), although the other vertebrate groups followed different trends. Additional analyses of elevational species richness and robust productivity data will shed more light on how critical productivity trends are to plants and animals.

\section{Other interacting biotic and abiotic processes}

Various biological processes have been proposed to explain patterns in species richness, including competition (Terborgh and Weske, 1975), source-sink dynamics and ecotone effects (Terborgh, 1985; Lomolino, 2001), and habitat heterogeneity and habitat complexity (Terborgh, 1977). For ecotones - locations on the gradient of major transitions between habitats - these zones are predicted to harbour more species due to overlapping range limits or due to source-sink dynamics (Table 1; Terborgh, 1985; Lomolino, 2001). The dominant ecotones are predicted to have the highest diversity, whereas minor peaks in diversity are expected at minor ecotones. Some biological interactions that are thought to increase diversity, like habitat heterogeneity, predict positive relationships; whereas interactions thought to decrease diversity, like competition, predict negative relationships (Table 1). Tests of these processes on elevational diversity patterns are few due to the difficulty in defining critical characteristics as well as measuring these traits for all species along a large spatial gradient. See also: Interspecific Competition

\section{Evolutionary history}

Evolutionary rates hypotheses are less developed elevationally than latitudinally (Wiens et al., 2007; McCain, 2009). Owing to a lack of species level, time-calibrated phylogenetic trees, speciation rate and extinction rate data 
for each mountain, many evolutionary hypotheses like the time-for-speciation are not testable along many elevational gradients (Wiens et al., 2007). But some general predictions exist for evolutionary trends (McCain, 2009). Static evolutionary models propose a region on mountains where conditions promote speciation and dampen extinction risk, and therefore predict a single diversity optimum. For example, if speciation is highest at the mountain base and declines with elevation, and extinction is highest at the mountain top and decreases towards the base, then the evolutionary optimum for diversity would occur at mountain bases globally. Single, consistent diversity optima are the general prediction of all static evolutionary models proposed to date (e.g., models in Brown, 2001; Heaney, 2001; Lomolino, 2001). If evolutionary factors generating montane diversity are strongly contingent on local fauna, conditions and biogeographic history, then no consistent, global signals in elevational diversity are predicted. Such a historical contingency would predict a lack of consistent patterns globally or only regionally consistent patterns. Lastly, niche conservatism proposes that climatic conditions within which a taxon evolved - tropical-like conditions for most modern groups and species - should be conserved in the present (Wiens and Donoghue, 2004). Thus, the basic elevation trend that niche conservatism predicts is maximum bird diversity in the warmest, wettest conditions on mountains; the same general pattern as that of ECM (McCain, 2009). See also: Diversity of Life; Diversity of Life through Time

\section{Conclusions}

Elevational gradients hold enormous potential as we endeavour to understand the factors underlying global biodiversity: there are thousands of gradients across the globe with varying climatic, spatial, historical and biotic settings, and the variability in floral and faunal species richness to these factors gives the basis to tease apart the most important drivers based on consistency and differences of diversity trends among mountains. Elevational species richness follows four main patterns - decreasing, low plateau, low plateau with a mid-elevational peak and mid-elevational peaks. So far the predominate factors underlying this variability appear to be climatic and specific to each taxonomic group (McCain, 2005, 2007b, 2009, 2010). But much more research is necessary to pinpoint the building blocks of elevational species richness patterns, emphasising the necessity of protecting intact montane gradients worldwide of research and for species protection. Lastly, as our climate gradually warms and climatic patterns change, the effects on montane communities of plants and animals will clearly be shifting in response. Elevational gradients serve as baselines for comparison of population declines, range shifts and extinction risks (Parmesan, 2006). See also: Conservation Biology and Biodiversity; Conservation of Biodiversity

\section{References}

Barry RG (2008) Mountain Weather and Climate. Cambridge, UK: Cambridge University Press.

Brehm G, Suessenbach D and Fiedler K (2003) Unique elevational diversity patterns of geometrid moths in an Andean montane rainforest. Ecography 26: 456-466.

Brown JH (1971) Mammals on mountaintops: nonequilibrium insular biogeography. American Naturalist 105: 467-478.

Brown JH (2001) Mammals on mountainsides: elevational patterns of diversity. Global Ecology and Biogeography 10: 101-109.

Brown JH, Gillooly JF, Allen AP et al. (2004) Toward a metabolic theory of ecology. Ecology 85: 1771-1789.

Brown JH and Lomolino MV (1998) Biogeography, 2nd edn. Sunderland, MA: Sinauer Associates, Inc.

Bryant JA, Lamanna C, Morlon H et al. (2008) Microbes on mountainsides: contrasting elevational patterns of bacterial and plant diversity. Proceedings of the National Academy of Sciences of the USA 105: 11505-11511.

Colwell RK, Rahbek C and Gotelli NJ (2004) The mid-domain effect and species richness patterns: what we have learned so far? American Naturalist 163: E1-E23.

Evans KL, Warren PH and Gaston KJ (2005) Species-energy relationships at the macroecological scale: a review of the mechanisms. Biological Reviews 80: 1-25.

Gaston KJ (2000) Global patterns in biodiversity. Nature 405 : $220-227$

Gotelli NJ and Colwell RK (2001) Quantifying biodiversity: procedures and pitfalls in the measurement and comparison of species richness. Ecology Letters 4: 379-391.

Grinnell J (1917) The niche-relationships of the California thrasher. Auk 34: 427-433.

Grinnell J, Dixon J and Linsdale JM (1930) Vertebrate Natural History of a Section of Northern California through the Lassen Peak Region. Berkeley, CA: University of California Press.

Grinnell J and Storer TI (1924) Animal Life in the Yosemite. Berkeley, CA: University of California Press.

Grytnes JA (2003) Species-richness patterns of vascular plants along seven altitudinal transects in Norway. Ecography 26: 291-300.

Grytnes JA, Heegaard E and Ihlen PG (2006) Species richness of vascular plants, bryophytes, and lichens along an altitudinal gradient in western Norway. Acta Oecologica 29: 241-246.

Grytnes JA and Romdal TS (2008) Using museum collections to estimate diversity patterns along geographical gradients. Folia Geobotanica 43: 357-359.

Grytnes JA and Vetaas OR (2002) Species richness and altitude: a comparison between null models and interpolated plant species richness along the Himalayan altitudinal gradient, Nepal. American Naturalist 159: 294-304.

Hawkins BA, Field R, Cornell HV et al. (2003) Energy, water, and broad-scale geographic patterns of species richness. Ecology $\mathbf{8 4}$ : 3105-3117.

Heaney LR (2001) Small mammal diversity along elevational gradients in the Philippines: an assessment of patterns and hypotheses. Global Ecology and Biogeography 10: 15-39.

Herzog SK, Kessler M and Bach K (2005) The elevational gradient in Andean bird species richness at the local scale: a foothill peak and a high-elevation plateau. Ecography 28: 209-222. 
Kessler M, Herzog SK, Fjeldsa J et al. (2001) Species richness and endemism of plant and bird communities along two gradients of elevation, humidity and land use in the Bolivian Andes. Diversity and Distributions 7: 61-77.

Lomolino MV (2001) Elevation gradients of species-density: historical and prospective views. Global Ecology and Biogeography 10: 3-13.

Martin PS (1958) A biogeography of reptiles and amphibians in the Gomez Farias region. Tamaulipas, Mexico. Miscellaneous Publications of the Museum of Zoology, University of Michigan 101: 1-102.

McCain CM (2004) The mid-domain effect applied to elevational gradients: species richness of small mammals in Costa Rica. Journal of Biogeography 31: 19-31.

McCain CM (2005) Elevational gradients in diversity of small mammals. Ecology 86: 366-372.

McCain CM (2007a) Area and mammalian elevational diversity. Ecology 88: 76-86.

McCain CM (2007b) Could temperature and water availability drive elevational species richness? A global case study for bats. Global Ecology and Biogeography 16: 1-13.

McCain CM (2009) Global analysis of bird elevational diversity. Global Ecology and Biogeography 18: 346-360.

McCain CM (2010) Global analysis of reptile elevational diversity. Global Ecology and Biogeography 19: 541-553.

McCain CM and Sanders NJ (2010) Metabolic theory and elevational diversity of vertebrate ectotherms. Ecology 91: 601-609.

Merriam CH and Stejneger L (1890) Results of a biological survey of the San Francisco Mountain region and desert of the Little Colorado, Arizona. North American Fauna 3: 1-136.

Mittelbach GG, Steiner CF, Scheiner SM et al. (2001) What is the observed relationship between species richness and productivity? Ecology 82: 2381-2396.

Nogués-Bravo D, Araújo MB, Romdal TS et al. (2008) Scale effects and human impact on the elevational species richness gradients. Nature 453: 216-220.

O'Brien EM (1993) Climatic gradients in woody plant species richness: towards an explanation based on an analysis of southern Africa's woody flora. Journal of Biogeography 20: 181-198.

Parmesan C (2006) Ecological and evolutionary responses to recent climate change. Annual Review of Ecology Evolution and Systematics 37: 637-669.

Pianka ER (1966) Latitudinal gradients in species diversity: a review of concepts. American Naturalist 100: 33-46.

Rahbek C (1995) The elevational gradient of species richness: a uniform pattern? Ecography 18: 200-205.

Rahbek C (1997) The relationship among area, elevation, and regional species richness in Neotropical birds. American Naturalist 149: 875-902.
Rahbek C (2005) The role of spatial scale and the perception of large-scale species-richness patterns. Ecology Letters 8: 224-239.

Romdal TS and Grytnes JA (2007) An indirect area effect on elevational species richness patterns. Ecography 30: 440-448.

Rosenzweig ML (1995) Species Diversity in Space and Time. Cambridge, UK: Cambridge University Press.

Sanders NJ (2002) Elevational gradients in ant species richness: area, geometry, and Rapoport's rule. Ecography 25: 25-32.

Srivastava DS and Lawton JH (1998) Why more productive sites have more species: an experimental test of theory using tree-hole communities. American Naturalist 152: 510-529.

Terborgh J (1977) Bird species diversity on an Andean elevational gradient. Ecology 58: 1007-1019.

Terborgh J (1985) The role of ecotones in the distribution of Andean birds. Ecology 66: 1237-1246.

Terborgh J and Weske JS (1975) The role of competition in the distribution of Andean birds. Ecology 56: 562-576.

Wake DB, Papenfuss TJ and Lynch JF (1992) Distribution of salamanders along elevational transects in Mexico and Guatamala. Tulane Studies in Zoology \& Botany 1(suppl): 303-319.

Whittaker RH (1952) A study of summer foliage insect communities in the Great Smoky Mountains. Ecological Monographs 22: 1-44.

Whittaker RH (1960) Vegetation of the Siskiyou Mountains, Oregon and California. Ecological Monographs 30: 279-338.

Wiens JJ and Donoghue MJ (2004) Historical biogeography, ecology and species richness. Trends in Ecology \& Evolution 19: 639-644.

Wiens JJ, Parra-Olea G and Wake DB (2007) Phylogenetic history underlies elevational biodiversity patterns in tropical salamanders. Proceedings of the Royal Society of London. Series B 274: 919-928.

\section{Further Reading}

Chen IC, Shiu HJ, Benedick S et al. (2009) Elevation increases in moth assemblages over 42 years on a tropical mountain. Proceedings of the National Academy of Sciences of the USA 106: 1479-1483.

Janzen DH (1967) Why mountain passes are higher in the tropics. American Naturalist 101: 233-249.

Moritz C, Patton JL, Conroy CJ et al. (2008) Impact of a century of climate change on small-mammal communities in Yosemite National Park, USA. Science 322: 261-264.

Watkins JE Jr, Cardelus C, Colwell RK et al. (2006) Species richness and distribution of ferns along an elevational gradient in Costa Rica. American Journal of Botany 93: 73-83. 